\title{
Brincar para quê? Escola é lugar de aprender! Estudo de caso de uma brinquedoteca no contexto escolar ${ }^{1}$
}

\section{Play, what for? A school is a place of learning! A case study carried out in a school toy library}

\section{I donezia Collodel Benetti*}

Centro Universitário Barriga Verde - UNIBAVE, Orleans, Santa Catarina, Brasil

O universo da brincadeira, da ludicidade e do ato de brincar tem despertado o interesse de pesquisadores e estudiosos, principalmente nas últimas décadas, com a preocupação de investigar e analisar questões que estão encapsuladas nos contextos de brincar. Assim, as pesquisas têm focado em temas tais como socialização, interação, afetividade, imaginação/fantasia, atenção, imitação, comunicação, simbolismo da brincadeira, desenvolvimento da linguagem, do pensamento, da concentração, espaços lúdicos, terapêutica do brincar, entre outras tantas possibilidades.

Em sintonia com interesses sobre a questão da brincadeira e do ato de brincar, Leila Lira Peters, orientanda da professora Andrea Zanella e co-orientada de Gilles Brougère, investe tempo para debruçar-se sobre essa temática, investigando assuntos relacionados à constituição do brincar no espaço social de uma brinquedoteca escolar, procurando possíveis contribuições para o processo de formação dos sujeitos envolvidos neste cenário. Com a perspectiva de que o brincar é uma condição essencial para o desenvolvimento da criança, e de que é fundamental que se valorize esse ato e, também, a expressão da infância, a autora busca, com este trabalho, problematizar questões que envolvem: a) a justificativa de uma brinquedoteca no contexto escolar, b) a função de um espaço como este na escola, c) as experiências e as possíveis aprendizagens proporcionadas por este espaço, d) as contribuições para o processo de formação de sujeitos que freqüentam tais contextos, e) os sentidos atribuídos ao brincar e à brinquedoteca escolar, e f) a função do professor neste cenário de ludicidade, em uma pesquisa que tenta entender o que acontece quando crianças e adultos se engajam no cenário de atividades rotineiras de uma brinquedoteca escolar.

Então, para ancorar as complexas questões albergadas no trabalho proposto, a pesquisadora apropriou-se do legado de teóricos 
reconhecidos, que foram convidados a contribuir com seus imprescindíveis aportes científicos, conceituando e amparando suas ideias. Então, ela trouxe para o universo das 92 crianças frequentadoras da brinquedoteca escolar de uma escola desdobrada municipal, em Florianópolis, SC, a polifonia das vozes de vários estudiosos, predominantemente as de Vygotski e Bakhtin que, neste trabalho, se misturam a muitas outras vozes - das próprias crianças e das suas respectivas famílias, da comunidade escolar e da própria pesquisadora - cada um trazendo em sua bagagem a síntese de múltiplas vozes, incluindo a heretoglossia, que dialogaram entre si, enriquecendo o processo e o resultado desta pesquisa.

Com tanta riqueza distribuída nas 286 páginas desta obra, é importante enfatizar que o leitor tem a satisfação de usufruir e se beneficiar da vivacidade destas forças de natureza dialógica, bem como da preciosidade da qualidade coletiva das interações individuais povoadas de intenções, engendradas neste contexto. Situação esta que permite, através do (des)empenho de seus "atores", que o mesmo mergulhe nesta orquestração vocal, na tarefa de emprestar, também, sua multiplicidade de vozes ao tentar dialogar com o texto, penetrar em conceitos, analisar a imbricação das vozes ali apresentadas, incluindo a bifurcação implícita existente entre a pesquisadora, as comunidades envolvidas, e 0 grupo sob investigação. Na verdade, um grande coral que, sem dúvida, serve de ferramenta para desvendar novos insights dentro dos vários níveis e justaposição de vozes que povoam este trabalho, refletindo e refratando palavras, ideias/intenções, sentidos e realidades.

Para deleite do leitor, a pesquisadora traz, em linguagem acadêmica - porém de fácil compreensão para pessoas leigas - conceitos da abordagem histórico-cultural, os quais preconizam que brincar é uma atividade humana, e seu conteúdo é consequência dos aspectos do desenvolvimento histórico da sociedade, os quais ditam e datam as condições sociais de um determinado tempo e lugar. Baseada em Vygotski, a autora pontua que a brincadeira consubstancia a relação com o outro e com a cultura que, assim engendradas, promovem desenvolvimento. Sendo a criança/sujeito o resultado direto desta cultura, ao desenvolver suas habilidades, faz através das interações sociais, onde cultura e comunidade, num processo colaborativo, têm papel fundamental no seu desenvolvimento, uma vez que o processo de apropriação da cultura é fruto da imersão do sujeito na multiplicidade de sentidos oferecidos pelo contexto, sendo estes reorganizados e re-elaborados, de acordo com a maneira como cada um apreende o que está posto, ressignificando-o e intervindo na realidade de seu momento.

É nesta linha de pensamento que a pesquisadora afirma que não existe a possibilidade de as brincadeiras serem realizadas à margem do real, deixando suas marcas nos sujeitos envolvidos. Sendo as 
crianças/sujeitos co-autore/as e co-produtore/as ativos desta cultura, que envolve, também, as atividades de brincar, as quais compreendem um universo que estabelece uma contraposição entre a fantasia/imaginação e a realidade - com significados e ações descolados daqueles habitualmente vinculados ao cotidiano - elas figuram como protagonistas de diferentes situações, que são (re)inventadas, (re)postas e (re)propostas, sendo o ato de brincar um agente emancipador, que possibilita, à criança, a perspectiva de criação de outras realidades, que vão além do imediato, cruciais para o desenvolvimento de processos psicológicos superiores.

Em outras palavras, uma situação imaginária permite a transposição do mundo real - dominado por objetos e ações - para um mundo dominado pelo significado onde, através da brincadeira simbólica e imaginativa, operada pelo impulso imediato, a criança cria mundos fantásticos e explora novas maneiras de combinar coisas e, assim, desenvolve um repertório de novas ideias, ao atribuir diferentes funções e significados aos objetos/realidades que a cercam, através da transformação, do exagero, das abstrações e inversões, dos condensamentos, reduções, e absurdos, em permanente movimento de extrapolação e transgressão da realidade. $E$, ao engajar-se em atividades de faz de conta - organizadas pelo signo linguístico imitando o que observam no mundo real, a criança apropria-se destas para produzir novos sentidos, criar novos significados e diferentes maneiras de compreender o mundo.

Seguindo este fluxo de ideias, além de desenvolver competências sociais e cognitivas, as fantasias elaboradas pelo ser que brinca estão vinculadas às suas emoções - componente-chave para 0 desenvolvimento da criatividade - e estreitamente ligadas as suas experiências, na proporcionalidade de que quanto maior e mais variadas forem as vivências, mais ricas serão as imagens criadas no mundo de fantasias da criança. Assim, o repertório adquirido - neste caso, simbiótico à imaginação - permite escolhas e re-elaborações destas imagens, tendo em vista os sentimentos, afetos e vontades do sujeito, que tem a liberdade de atribuir novos sentidos as suas (re)criações e ações.

Ainda com base em Vygostski, a autora desta obra aponta que as experiências e os sentimentos, vinculados, têm a função de mitigar a tensão entre desejos e possibilidades - entre a busca da realização daqueles e o fato de haver dificuldades e, muitas vezes, impossibilidades para realizar estas - no mundo da criança, onde os desejos não realizados podem ser realizáveis, impulsionando os processos de criação infantil. Estes processos permitem 0 engajamento da criança em um movimento singular de aventuras e triunfos, que vão além dos limites da realidade, contribuindo para o desenvolvimento de regras sociais e habilidades linguísticas, que são adquiridas através das brincadeiras. 
Neste espectro, os ganhos advindos destes processos e apropriações, juntamente com a exposição à cultura/contexto, são debitados no processo de constituição do sujeito/criança, pois através do ato de brincar o ser em constituição estabelece trocas sociais, cria uma atmosfera que encapsula o sentimento de pertença, bem como vínculos afetivos vitais no processo de subjetivação do mesmo. Neste cenário, o brincar prepara as crianças para a vida futura, sendo potencialmente constituidor de Zonas de Desenvolvimento Proximal, promovendo desenvolvimento, decorrente das experiências vivenciadas pelas crianças.

Amparada em Vygotsky, a pesquisadora baseia-se no conceito de que as atividades humanas têm lugar em contextos socioculturais e são mediadas pela linguagem e outro sistemas de símbolos, artefatos que dão suporte a propósitos que tornam possíveis a integração e 0 desenvolvimento da criança no contexto de sua cultura. $E$, além disso, transformam a maneira como a mente da criança vai sendo formada e, como resultado do uso de tais artefatos, as crianças primeiramente com ajuda de auxiliadores mais experientes, e mais tarde independentemente - desenvolve funções mentais complexas que são intencionais, autorreguladas, e mediadas pela linguagem, a mais importante "ferramenta" mental para a facilitação da aquisição de outros símbolos mentais, determinados pela cultura.

Assim, mediado por signos culturais e considerado como a principal atividade da criança, o ato de brincar, dentro da perspectiva deste trabalho, é uma atividade promotora da apropriação de modos de agir e de relacionar-se da criança consigo mesma, com os outros e com os objetos, sendo potencialmente promotor de desenvolvimento, aqui entendido como um processo dialético complexo, marcado por metamorfoses, avanços, retrocessos, saltos e recuos. E, também, é demarcado pela cumulação qualitativa e dialética, sendo determinado muito mais pelo meio cultural onde a criança/sujeito cresce e se desenvolve, do que por fatores biológicos de bases inatas, maturacionistas e naturalizantes do psiquismo.

Então, utilizando-se dos pressupostos teóricos de perspectiva histórico-cultural, o desenvolvimento metodológico deste trabalho está pautado na crença da superação das dicotomias preconizadas pela ciência positivista, e mostra que a escolha do referencial teórico da pesquisadora está ancorada no pressuposto da realidade humana com dimensão de totalidade integradora, sem separar ciência/vida, internos/externo, individual/social, sujeito/objeto, fornecendo meios para uma compreensão da condição humana que foge da fragmentação, expulsando o sujeito da sua humanidade. Com estes argumentos, ela identifica-se com as teorias de Vygotski e Bakhtin, fundamentadas no materialismo histórico, e gestadas numa atmosfera de insatisfação com os reducionismos apregoados pelas concepções empiristas e, portanto, dicotômicas e fragmentárias. 
Em Vygotski e Bakhtin/Volochínov, a arquiteta desta obra sustenta sua convicção sobre a imprescindibilidade dos signos - em especial da linguagem verbal - como instrumentos psicológicos fundamentais na constituição do psiquismo humano, com função de atuar sobre ele modificando-0. Em sua tese, ela compartilha com estes teóricos o fato de a constituição do sujeito ser semioticamente mediada, já que sem material semiótico não há possibilidade de atividade psíquica. Nesta concepção, o psiquismo fica situado entre o organismo e o mundo exterior, e a forma de mediar a relação entre estes dois universos se materializa nos signos; na linguagem.

A linguagem - instrumento do pensamento e um dos signos mais importantes para promover e estimular o desenvolvimento psicológico - funciona como instrumento de comunicação. Ela deve ser compreendida em seu contexto, já que os signos não têm existência independente fora das práticas sociais dos seres humanos, emergindo como parte da atividade humana, oferecendo significados que servem de base para a significação das experiências significações estas que constituirão a consciência mediando as formas de agir e pensar dos sujeitos; e a linguagem, enquanto signo, faz a mediação não só do pensamento mas também da própria produção e reprodução da sociedade humana.

Em harmonia come este pensamento, Peters está convicta de que é através da função comunicativa - estabelecida nas interações sociais - que a criança/sujeito se apropria do mundo em seu entorno, já que a comunicação é promotora de cenários que possibilitam trocas, "negociações", e (re)interpretações das informações, conceitos e significados, construídos no processo social e histórico. Ciente disso, ela enfatiza que, neste sentido, a ação dos indivíduos é considerada a partir da ação entre indivíduos, e o sujeito só é sujeito no contexto social.

Então, assumindo que o psiquismo humano é constituído no social, num processo interativo possibilitado pela linguagem, a pesquisadora, com base em Bakhtin, traz para a arena de seu trabalho a questão de que os discursos entre os sujeitos se confrontam - neste caso, tanto do pesquisador quanto da/os crianças/sujeitos pesquisada/os influenciando-os mutuamente. Nesta orientação, sua pesquisa transita em uma via de mão dupla, relacional entre sujeitos e, portanto, dialógica, onde pesquisadora e pesquisados são parte integrantes do processo de investigação, construindo sentidos, neles se re-significando e se transformando durante o processo.

Assim, no complexo contexto da brinquedoteca escolar, as questões de pesquisa possibilitaram a tessitura de relações com diferentes universos, e com as diferentes possibilidades de relações dialógicas, em seus matizes. O presumido, abarcando não somente o dito, mas também o "não-dito"/os silêncios, as lacunas, e o extralinguístico expressam sentidos e comunicam o excedente de visão - o que não 
vejo, mas que o "outro" vê - a noção de diálogo como diálogo inacabado, o discurso em movimento/sua contradições, tensões e instabilidades. Na opinião da autora, tudo isso serviu de base para a retomada do processo de produção de sentidos, os quais permitiram a compreensão da atividade do brincar, patrocinada pelos sujeitos que protagonizaram o cenário dialógico e polissêmico, fundamental para os achados deste trabalho, que embarcou na narrativa dos sujeitos, expressa durante as brincadeiras das crianças.

Ao observá-las em relação dialógica, na dimensão variada das suas discursividades, foi possível coletar o material necessário para compreender um pouco do processo que envolveu gestos, movimentos, adesões/resistências, transgressões, falas, vozes, harmonias/dissonâncias, prazer/desprazer, compartilhamentos/recusas, interpretações, recriações, resignificações, negociações, formulação de hipóteses, presentes na produção discursiva de vozes sociais plurilíngues. Uma verdadeira "Torre de Babel" de linguagens entrecruzadas, e revestidas de sentidos próprios do lugar social, onde os sujeitos sob investigação estavam imersos, repleto de palavras, ecos e enunciados de outros, e de visões de mundo e tendências que, provavelmente, se cruzavam, se encontravam e se separavam.

É importante enfatizar que, apesar de fazer parte do cenário, a pesquisadora procurou ter um olhar exotópico. Esta decisão assume uma posição de exterioridade da autora/criadora em relação ao contexto da pesquisa - necessário à análise, ao encadeamento e à construção dos trabalhos realizados, tentando manter um posicionamento do "eu", distanciado em relação ao "outro"/sujeito/lugar, com a finalidade de compreender como este "outro", a partir da visão dele que é única, se coloca em relação ao mundo e, assim procedendo, a autora faz o movimento de retorno a sua posição, acrescida da experiência do "outro", porém trazendo na bagagem os conteúdos/substratos daquilo que o "outro" não vê, dando ao "outro"/sujeito/lugar um novo acabamento, procedimento fundamental para atribuir outro foco e outra perspectiva de olhar. Concluindo, a presente tese oferece aos leitores um estudo rico e abrangente sobre uma brinquedoteca no contexto escolar. No cenário da pesquisa, o leitor encontra assuntos relacionados à temática da infância e do brincar como um direito infantil, bem como da criança enquanto sujeito de direitos, a partir da modernidade, dentro do contexto brasileiro. Além disso, a pesquisadora busca entender a constituição do ato de brincar no contexto da binquedoteca escolar, os sentidos a ela atribuídos, as experiências e aprendizagens proporcionadas por este espaço social, as contribuições oferecidas por ele para o processo de formação dos sujeitos que o frequentam, e a função do professor neste contexto. 
Sem sombra de dúvidas, além de abrangente, a autora conseguiu elaborar um trabalho multidisciplinar que interessa a várias áreas do conhecimento, apresentando a brinquedoteca como um lugar de tensões e contradições - ocorridas entre adultos, adultos e crianças, e entre as próprias crianças, gerando experiências e aprendizagens para todos os que estiveram envolvidos no processo de pesquisa, incluindo a pesquisadora. Defendida em dezembro de 2009 e disponibilizada no site da UFSC em 2010, esta tese está recomendada para todos aqueles que se interessam por questões relacionadas ao brincar, como um universo rico para o desenvolvimento infantil, uma vez que traz experiências que podem impulsionar os leitores a refletir sobre os pretensos saberes sobre a infância, (re)pensar práticas cotidianas, e (des)construir alguns modos de olhar e pensar a criança, a infância e o brincar, historicamente construídos, uma vez que esta construção afeta e transforma o modo como os adultos se relacionam com as crianças na sociedade.

\title{
Referência
}

PETERS, L. L. Brincar para quê? Escola é lugar de aprender! Estudo de caso de uma brinquedoteca no contexto escolar. 2009. 286f. Tese (Doutorado em Psicologia) - Universidade Federal de Santa Catarina, Florianópolis.

\author{
Endereços para correspondência \\ I donezia Collodel Benetti \\ Centro de Filosofia e Ciências Humanas. Campus Universitário - Trindade. \\ Florianópolis - SC. CEP: 88040-500 \\ Endereço eletrônico: idonezia@hotmail.com
}

Recebido em: 09/01/2012

Reformulado em: 15/04/2012

Aceito para publicação em: 15/04/2012

Acompanhamento do processo editorial: Alexandra Cleopatre Tsallis

\footnotetext{
Notas

* Psicóloga, Psicopedagoga e Mestranda em Psicologia na Univerisidade Federal de Santa Catarina.

${ }^{1}$ Título da tese de doutorado de Leila Lira Peters, orientada pela Prof. Dra. Andrea Zanella e defendida na Universidade Federal de santa Catarina leilapeters@yahoo.com.br.
} 